\title{
GOAL CLARITY AND TRUST IN MANAGEMENT IN EDUCATIONAL MERGERS
}

\author{
T May \& RB Mason, Durban University of Technology, South Africa
}

\begin{abstract}
Purpose: The aim of this paper is to explore employees' opinions on goal clarity, trust in management and perceptions of organisational readiness for change in the context of the changes caused by the merger to form the Durban Institute of Technology (DIT) in order to increase knowledge about the human aspects of mergers.
\end{abstract}

Design/Methodology/Approach: A survey of staff was conducted, with a sample of respondents completing a questionnaire, which investigated whether or not there were relationships among the change variables, namely goal clarity, trust in management and perception of organisational readiness for change.

Findings: The key finding of the study is that the goals of the institution were not clarified sufficiently during the change process at DIT. The correlation of goal clarity, trust in management and perceptions of organisational readiness for change were all significant at the $p<0.01$ level; and the direction of the relationship between the variables was strongly positive (between 0.7 and 1.0).

Implications: The results suggest that management success in identifying organisational goals clearly during a change initiative could help improve employees' attitudes, thereby increasing the likelihood of merger success, and minimising the negative reactions and staff dissatisfaction often associated with mergers.

Originality/Value: Although there is a lot of research in the generic field of mergers and considerable research into mergers in higher education, both overseas and in South Africa, there is a lack of research in the human aspects of mergers. This is especially true of the three key change variables of perceptions of readiness for change, goal clarity and trust in management. Furthermore, what research there is has not focussed on the opinions of individual employees, but on the opinions of trade unions and student representatives. Therefore, this study contributes to filling an important gap in the literature on higher education mergers in South Africa.

Key words and phrases: Readiness for change, trust in management, goal clarity, mergers, higher education.

\section{INTRODUCTION}

As communities settle into the new millennium, organisational change continues at a rapid pace worldwide (Kotler, Wong, Saunders \& Armstrong, 2005:87). Management scholars are aware that this level of change in both public and private sectors may have a negative impact on employee attitudes and productivity (Weber \& Weber, 2001:291).

Bennett and Durkin's (2000:126) observation is that organisations tend to be very good at planning and orchestrating the technical and structural aspects of change, but poor at guiding and supporting the human side - the personal re-orientation associated with change. Furthermore, most mergers and acquisition strategies are still dominated by financial analyses, legal considerations and power plays by dominant groups, as individuals rush for positions and influence, rather than focusing on the inherent dysfunction that can emerge in the combined organisation (Buono, 2003:90).

In July 1999, the second post-apartheid Minister of Education in South Africa (Professor Kader Asmal) announced the transformation and restructuring of the higher education system stipulating that the new system should comprise 21 higher education institutions instead of 36 (Durban Institute of Technology, 2002:1). The Higher Education Act 101 of 1997, section 23, states that the Minister may, after consulting the Council on Higher Education (CHE) and by notice in the Gazette, merge two or more public higher education institutions into a single public higher education institution. The government embarked on a 
programme of restructuring the education system on the principles of equity, human rights, democracy and sustainable development, in order to address the inequalities of the past (South Africa, 1997:1-251). According to Wyngaard and Kapp (2004:189), little (if any) research has been done in South Africa on the human psychological experiences of academic staff in completed higher education mergers. Generic studies of mergers abound (Jansen, 2004:5 and Mfusi, 2004:105) and there is a body of literature on higher educational mergers in other countries, such as Australia (Pick, 2003:300) and the United Kingdom (Rowley, 1997: 254). None of these studies, however, cover the change management process. Regarding generic mergers, LaClair and Ravi (2002:17) suggest that success or failure of a merger depends on how well change is managed, and it is critical that employees trust management. However, there are few (if any) systematic studies evaluating the change management process in terms of the goal clarity, trust in management and perceptions of organisational readiness for change of merging or merged higher education institutions in South Africa. A study of higher education mergers (including the DIT merger) by Jansen (2002:139), indicated the opinions from employee unions and student representatives on the effects of the merger, but did not address the attitudes and opinions of individual staff members. The findings of the study indicated that, beyond governmental or legal requirement, the objectives of mergers were not clear.

The main purpose of this paper is to evaluate the change management process undertaken by DIT in order to assist in addressing apparent staff dissatisfaction. The study was conducted in November and December 2003, seeking opinions and attitudes of staff on the merger process. Although the importance of issues such as goal clarity and trust in management is obvious during any change management process, it is essential to note the lack of, or insufficient, attention paid to these issues and the fact that almost no empirical research has been conducted into them in higher education mergers.

This paper reports on a research study of the change management process of the first voluntary merger of two Technikons in South Africa. Specifically, the study examined the degree of goal clarity, trust in management and perceptions of organisational readiness for change present in the staff of the merged institutions, as these are key issues in a successful change process. These issues will be discussed in the literature review to follow. Thereafter, the method that was used to conduct the research is explained, and then the results, the hypothesis tests and some qualitative results are presented. These results are then discussed in terms of the variables and their interrelationships, and finally conclusions are drawn and some recommendations for further research are made.

\section{LITERATURE REVIEW}

In this section, literature on the two variables that are hypothesised to influence perceptions of readiness for change (namely, goal clarity and trust in management) are reviewed. Then the literature on perception of readiness for change is reviewed as this is perceived to be critical to the success of merger implementation. From these reviews, the research hypotheses are developed.

\section{Goal Clarity and Trust in Management}

According to Weber and Weber (2001:294), goal clarity is the degree to which employees precisely understand an organisation's goals and the means for achieving those goals. The literature suggests ways in which goals may be clarified successfully and trust maintained or enhanced. A vision should be articulated in a few forceful and memorable words (Covington, 2001:15 and Moran \& Brightman, 2001:112). A clear vision should be provided because employees like certainties and much hostility to change may simply be the result of a lack of clarity (Bill, 2002:54 and Stauffer, 2003:3). Pounder (2001:282) suggests that the leader 'walks the talk' and aligns performance with words. The change leadership group should exhibit strong alignment to the desired future, and should develop and communicate a vision. A successful merger is characterised by visible and robust management that is able to collect the different sub-cultures, as well as create a joint feeling of identity and organisational structure (Swanepoel, 2005:5). Furthermore, when people know why the change is needed, they can figure out what to change and how to change it (Covington, 2001:15). 
Such change should combine both top-down and bottom-up initiatives (Roseel, 2005:254). Change must be top-down to provide vision and create structure, and bottom-up to strengthen participation and generate support. If the whole organisation is not committed to the change effort, it will fail. The whole organisation must be pulling in the same direction to achieve the change initiative goals it has set (Moran \& Brightman, 2001:113). By creating trust and preventing an 'us versus them' mentality, both management and employees can create the proper behavioural consequences that lower resistance to change and drive the behavioural process to maximum fulfilment (Barret, 2000:28).

According to Borden (1997: 6), most problems occur because of a lack of trust and communication. Trust in management can be defined as the willingness of employees to be vulnerable to the actions of executive management based on the expectation that the other will perform a particular action important to the truster, irrespective of the ability to monitor or control management (Chawla \& Kelloway, 2004:487).

During a merger, it is not the nuts and bolts of joining two organisations together that cause the biggest problems; it is ignoring the human element that brings an otherwise logical merger to its knees. It is suggested that regular informal discussions are necessary in making a merger work. People are more eager to cooperate and support corporate decisions if they know that they will be informed during the process (Borden, 1997:6). Furthermore, McLagan (2002:56) suggests that people can consent to changes that may affect them adversely if they believe the change is right and procedural justice was followed. Trust in management entails the creation of an atmosphere where trusting communication can take place as well as a reduction of speculation and unfounded fears (Weber \& Weber, 2001:291 and Steyn \& de Klerk, 2005:157). According to Roseel (2005:257), awareness and knowledge of the pitfalls of change management in multicultural environments is essential in order to encourage maximum dialogue as well as negotiations at the correct level.

\section{Perceptions of Organisational Readiness for Change}

According to Shalem (2001:24), there is limited research relating to readiness for change. The process for creating an ideal atmosphere of change can be approached in a three-step manner. Firstly, it is essential that management demonstrate focus and commitment to change and improvement. Secondly, management must develop an agenda that continually addresses change issues. Finally, management must instil the desire for change and improvement in employees (Roberts, 2003:3). Successful implementation of planned change may depend upon a work environment that is conducive to innovation and change (Weber \& Weber, 2001:292 and Mohyeldin \& Suliman, 2001:50).

According to Weber and Weber (2001:292), employee perceptions explore how much an organisation values innovation and how likely it will be that the organisation will be adaptive to new opportunities. An effective change model should accommodate and encourage on-going interactions, based on experimentation and learning, rather than being a static process (White, 2000:165). Senge (2006:297) recommends that an effective change model must foster local innovation that helps organisations respond better to unexpected opportunities and build on local innovations over time. This type of strategy would be a better way to respond to a turbulent environment. According to Francis, Bessant and Hobday (2003:23), the challenges of an uncertain or turbulent environment are such that, unless organisations engage in product/service innovation and the ways in which they create and deliver these offerings, there is a probability that their survival will be in doubt. The essential ingredients of survival in today's global markets are productivity, quality, creativity, and innovation. Role behaviours, such as creativeness and innovation, keep an organisation competitive (Mohyeldin \& Suliman, 2001:51).

"Courageous and decisive leadership can inspire an organisation to overcome difficult situations or to take quick action. In contrast, a tendency to over-analyse data or to take a 'wait-and-see' attitude may cause a firm to lose ground to competitors and may exacerbate internal problems “(Appelbaum, St-Pierre \& Glavas, 1998:290).

Managers are nominated to lead the employees to betterment, while at the same time co-ordinating dayto-day efforts to get the job completed. Managers set the tone and swiftness for employees. By their 
actions and behaviour, managers develop an atmosphere which is either stifling, encouraging the maintenance of status quo, or vibrant with enthusiasm for change and improvement (Roberts, 2003:3). Whether employees perceive an organisation as ready for change or not is thus dependent on the activities of the organisation's managers.

The above findings suggest that the success of a merger would be influenced by the employees' perceptions of whether it is ready for change, and this readiness for change would be influenced by the goal clarity and trust in management present in the merging organisations. Therefore, the objective of this research study is to identify the level of goal clarity and trust in management, and to ascertain whether a relationship existed between these two variables and the perceived readiness for change at the time of the merger of ML Sultan Technikon and Natal Technikon to form the Durban Institute of Technology. As a result, the authors posited that the organisations would be perceived as not ready for change, and both goal clarity and trust in management would be low. Thus, the authors hypothesised that positive relationships would exist between perceived readiness for change and goal clarity, between perceived readiness for change and trust in management, and between goal clarity and trust in management.

\section{METHOD}

The method used for this study was a questionnaire-based survey of DIT staff. This section explains how the study was conducted in terms of the sample, the derivation of the questionnaire and the collection and analysis of the data.

\section{Data Collection and Sample}

The method of data collection selected was the interviewing/communication process (Cooper \& Schindler, 2001:295). The respondents were questioned by means of a self-administered questionnaire that was based on a questionnaire from Weber and Weber (2001:298), and therefore the data collection tool was accepted as valid and reliable. The self-administered questionnaire was pilot tested on twelve respondents, with no problems being encountered.

The research population included both academic and administrative staff members of the merged institutions. An e-mail requesting permission to distribute the questionnaire was sent to the Heads of Department of 110 departments within DIT on various campuses. Thereafter, a questionnaire was distributed to 600 employees from a population of almost 1000 permanent employees. Struwig and Stead (2001:119) suggest that a sample size of 150 to 200 can provide an acceptable reflection of the population. Each department's secretary assisted with the distribution of the questionnaire. From the names of all permanent staff in each department, $60 \%$ were randomly drawn. The secretary then inserted the questionnaires in the relevant staff members' mail boxes/pigeonholes. Once the questionnaire had been completed, it was returned to the secretary and collected by the researcher. This first 'mailing' resulted in a response of 188 completed questionnaires (31\% response).

A follow-up memorandum was e-mailed to the DIT electronic notice board to thank those who had responded and to encourage others to respond. This exercise was done twice to encourage participation. The second mailing resulted in 24 new responses $(4 \%)$ and the third mailing resulted in six responses (1\%). Eighteen questionnaires were rejected due to completion errors. Therefore, the final useable sample was 200 questionnaires (33\% of mailing and $20 \%$ of population).

\section{Data Collection Instrument}

The scaling technique utilised in the questionnaire was a non-comparative, itemised Likert type rating scale (Welman, Kruger \& Mitchell, 2005:156). The utilisation of the Likert Scale, ranging from "strongly disagree (1)", "disagree (2)", "neither agree nor disagree (3)", "agree (4)", to "strongly agree (5)", enabled the gathering and evaluation of interval data. Higher scores reflected higher reported levels of the variable. 
Self-administered questionnaires ensured access to a large number of respondents, and also guaranteed the anonymity of the respondent. This was important in the questionnaire since trust in management is a sensitive issue and the honesty of answers could be suspect if anonymity could not be guaranteed.

The SPSS Version 9 statistical program was used for the analysis of the data. Descriptive statistics, including central tendency and frequencies, and inferential statistics, including correlation and one-way analysis of variance were used. All tests were carried out at the $\alpha=0.01$ level of significance and the $p$ values were used for significance testing. The reliability of the study was tested using reliability analysis. Cronbach's Alpha was computed as $0.9131(p=0.000)$. This indicates that there was a high degree of internal consistency amongst the test items.

\section{RESULTS}

The demographics of the sample were analysed to establish whether the DIT employees' perceptions were related to office location within the institution, the length of service, the functional division and former heritage employer. These descriptive statistics are shown in Table 1.

Table 1: Descriptive statistics of sample

\begin{tabular}{|l|l|l|l|l|l|l|l|}
\hline $\begin{array}{l}\text { Office } \\
\text { Location }\end{array}$ & $\begin{array}{l}\text { \% of } \\
\text { sample }\end{array}$ & $\begin{array}{l}\text { Length of } \\
\text { service }\end{array}$ & $\begin{array}{l}\text { \% of } \\
\text { sample }\end{array}$ & $\begin{array}{l}\text { Functional } \\
\text { division }\end{array}$ & $\begin{array}{l}\text { \% of } \\
\text { sample }\end{array}$ & $\begin{array}{l}\text { Previous } \\
\text { employer }\end{array}$ & $\begin{array}{l}\text { \% of } \\
\text { sample }\end{array}$ \\
\hline Steve Biko & 39.1 & $>15$ years & 22.2 & $\begin{array}{l}\text { Academic \& } \\
\text { research }\end{array}$ & 60.6 & $\begin{array}{l}\text { Technikon } \\
\text { Natal }\end{array}$ & 57.9 \\
\hline MLSultan & 31.0 & $\begin{array}{l}11 \text { to } 15 \\
\text { years }\end{array}$ & 15.7 & $\begin{array}{l}\text { Academic } \\
\text { support }\end{array}$ & 15.2 & $\begin{array}{l}\text { MLSultan } \\
\text { Technikon }\end{array}$ & 42.1 \\
\hline $\begin{array}{l}\text { Pieter- } \\
\text { maritzburg }\end{array}$ & 3.0 & $\begin{array}{l}6 \text { to } 10 \\
\text { years }\end{array}$ & 28.8 & Administration & 20.7 & & \\
\hline $\begin{array}{l}\text { City } \\
\text { campus }\end{array}$ & 8.1 & $\begin{array}{l}1 \text { to } 5 \\
\text { years }\end{array}$ & 29.8 & $\begin{array}{l}\text { Technical } \\
\text { support }\end{array}$ & 3.5 & & \\
\hline Ritson & 13.7 & $<1$ years & 3.5 & & & & \\
\hline Brickfield & 5.1 & & & & & & \\
\hline
\end{tabular}

In order to assess whether the demographic variables influenced the research variables, analysis was conducted testing all demographic variables using one-way analysis of variance. No significant differences according to demographics were identified, as is shown by Table 2, leading to the conclusion that the feelings of employees about goal clarity, trust in management and perceptions of organisational readiness for change were comparable across office location, length of service, functional area, and former employer; and furthermore no significant difference between academic and administrative staff was found.

Table 2: The relationship between main variables and demographic variables*

\begin{tabular}{|l|l|l|l|}
\hline Variables & Goal clarity & Trust in management & Organisational readiness \\
\hline Office location & 0.454 & 0.609 & 0.067 \\
\hline Length of service & 0.102 & 0.067 & 0.090 \\
\hline $\begin{array}{l}\text { Previous heritage } \\
\text { employer }\end{array}$ & 0.212 & 0.126 & 0.556 \\
\hline Functional Area & 0.917 & 0.703 & 0.813 \\
\hline
\end{tabular}

* Summary of sigma values: One-Way ANOVA.

\section{The Variables of the Research}

The survey was designed to identify the feelings of staff about the change management process, specifically goal clarity, trust in management and perceptions of organisational readiness for change. The 
employees also had an opportunity to describe their perceptions of conditions within the institution. Questions covered the three variables. Employees' perceptions about the three variables are summarised in Table 3 below.

Table 3: Summation of all responses to the questions on the three variables

\begin{tabular}{|l|l|l|l|l|l|l|}
\hline \multirow{2}{*}{$\begin{array}{l}\text { Question response } \\
\text { categories }\end{array}$} & \multicolumn{2}{|l|}{ Goal Clarity* } & \multicolumn{2}{l|}{ Trust in Management* } & \multicolumn{2}{l|}{ Readiness for Change* $^{*}$} \\
\cline { 2 - 7 } & $\mathbf{N}$ & $\%$ & $\mathbf{N}$ & $\%$ & N & $\%$ \\
\hline Strongly disagree & 215 & 27.0 & 240 & 30.1 & 240 & 30.2 \\
\hline Disagree & 294 & 36.7 & 226 & 28.3 & 279 & 35.1 \\
\hline $\begin{array}{l}\text { Neither agree nor } \\
\text { disagree }\end{array}$ & 191 & 24.0 & 150 & 18.8 & 192 & 24.2 \\
\hline Agree & & & & & & \\
\hline Strongly agree & 89 & 11.2 & 132 & 16.5 & 78 & 9.8 \\
\hline *Total responses & 7 & 1.0 & 50 & 6.3 & 5 & 0.6 \\
\hline O missing cases; 200 valid cases & 100.0 & 798 & 100.0 & 794 & 100.0 \\
\hline
\end{tabular}

${ }^{*}$ Each variable had four questions, multiplied by sample size of 200 - hence total response is close to 800.

Table 4 below provides the descriptive statistics for the three variables: goal clarity, trust in management and perceptions of organisational readiness for change.

Table 4: Descriptive statistics of the three variables

\begin{tabular}{|l|l|l|l|l|l|l|l|l|l|}
\hline Variable & N & Range & $\begin{array}{l}\text { Mini- } \\
\text { mum* }\end{array}$ & & $\begin{array}{l}\text { Maxi- } \\
\text { mum* }\end{array}$ & Mean & $\begin{array}{l}\text { Std } \\
\text { dev. }\end{array}$ & Variance & \multicolumn{2}{|l|}{ Skewness } \\
\cline { 7 - 10 } & & & & & & & & & \\
Statistic & $\begin{array}{l}\text { Std. } \\
\text { Error }\end{array}$ \\
\hline $\begin{array}{l}\text { Trust in } \\
\text { management }\end{array}$ & 198 & 14 & 4 & 19 & 8.89 & 3.23 & 10.43 & 0.328 & 0.173 \\
\hline $\begin{array}{l}\text { Perceptions } \\
\text { on readiness }\end{array}$ & 194 & 12 & 4 & 16 & 8.63 & 3.173 & 10.067 & 0.162 & 0.173 \\
\hline
\end{tabular}

${ }^{*}$ Four questions per variable measured on a 5 point scale $-5=$ strongly agree, $1=$ strongly disagree

Goal clarity: Table 3 indicates the employees' perceptions of how clear organisational goals were. Overall, most employees felt that goals were unclear $(64 \%)$, with only $12.2 \%$ feeling that goals were clear. The mean for goal clarity is closer to the minimum than to the maximum, which confirms that the feelings of employees about goal clarity were negative. The coefficient of variation is $36 \%$, which is below $40 \%$ and therefore indicates that the mean is moderately reliable. Goal clarity is positively skewed to the right, which indicates fewer relatively large values in the data set. There is a moderate skewness of 0.328 . Most of the data values are relatively small which further confirms that employees' feelings were negative.

Trust in management: Table 3 also indicates the employees' perceptions of trust in management. Overall, employees appeared to distrust DIT management but a split was apparent around whether or not management was treating employees with respect. While $58.4 \%$ (30.1\% plus $28.3 \%)$ of respondents distrust management, $22.8 \%$ (16.5 plus $6.3 \%$ ) in contrast indicated that they trusted management. The mean is once again closer to the minimum, which indicates that the employees do not trust management. The coefficient of variation is $32 \%$, which is below $40 \%$ and therefore indicates that the mean is moderately reliable. Trust in management is positively skewed to the right, which indicates that most of the data set values are relatively small. The moderate skewness of 0.235 further confirms the employees' feelings with regard to trust in management (see Table 4). The environment of distrust, as reflected in these results, is clearly not ideal to accomplish the objectives of the organisation. 
Readiness for change: Table 3 represents the perceptions of employees about organisational readiness for change. This is generally an indication of the perceptions on how people are managed within the institution. As indicated in the table, the overall impression tends to be negative, with $65 \%$ (that is $30.2 \%$ plus $35.1 \%$ ) disagreeing or strongly disagreeing that the organisation was ready for change. Generally, such responses indicate that employees feel the organisation is not ready for change.

The mean of 8.63 is closer to the minimum of 4 compared to the maximum of 16 , which confirms that the feelings of employees were negative (see Table 4). The coefficient of variation is $37 \%$, which suggests that the mean is moderately reliable. The variable is positively skewed to the right with a value of 0.162 . The moderate skewness further suggests that the employees of DIT perceived that the organisation was not ready for change.

\section{Testing of Hypotheses}

The testing of hypotheses was done utilising Pearson correlation. The Pearson correlation matrix indicates the direction, strength and significance of the bivariate relationship between the variables in the study. The correlations between the three variables are shown in Table 5 below.

Table 5: Pearson correlation relationships between the three variables

\begin{tabular}{|l|l|l|l|}
\hline \multirow{3}{*}{ Goal Clarity } & & Trust in management & $\begin{array}{l}\text { Perceptions on } \\
\text { readiness }\end{array}$ \\
\cline { 2 - 4 } & Pearson Correlation & $.732^{* *}$ & $818^{* *}$ \\
\cline { 2 - 4 } & Sig. (2-tailed) & .000 & .000 \\
\cline { 2 - 4 } & $\mathrm{N}$ & 196 & 192 \\
\hline \multirow{3}{*}{ Trust in management } & Pearson Correlation & - & $.739^{* *}$ \\
\cline { 2 - 4 } & Sig. (2-tailed) & - & .000 \\
\cline { 2 - 4 } & $\mathrm{N}$ & - & 193 \\
\hline
\end{tabular}

${ }^{*}$ Correlation is significant at the $p=0.01$ level (2-tailed).

Firstly, it was hypothesised that there would be a positive relationship between goal clarity and trust in management at DIT. Table 5 shows a strong, positive and significant relationship between the variables, indicating that hypothesis 1 can be accepted.

Secondly, it was hypothesised that there would be a positive relationship between goal clarity and the reported perceptions of organisational readiness for change at DIT. Table 5 again shows a strong, positive and significant relationship between the variables, indicating that hypothesis 2 can be accepted.

Thirdly, it was hypothesised that there would be a positive relationship between trust in management and the reported perceptions of organisational readiness for change at DIT. Table 5 also shows a strong, positive and significant relationship between the variables, indicating that hypothesis 3 can be accepted.

\section{Qualitative Data Analysis}

The questionnaire allowed for open-ended comment on the research issues. Analysis of this qualitative data resulted in four main themes of concern to the respondents emerging. Some respondents indicated that most of the problems emanated from lack of clarity in institutional goals. One respondent summarised the feelings as follows:

"If only management knew what they were doing, then we would know which direction we are heading. Two people doing the same job and earning way differently, very unhappy with management, not being able to sort out our problems. No one seems to help sort our problems any more". 
Insufficient communication emerged as a second theme. Poor communication manifested as rumours, which may also have contributed to lack of trust in management. The 'grapevine' seemed to have become entrenched within the organisation.

Ten respondents perceived that most decisions were not based on anything, and sometimes consultation was poor, if it existed at all. It would seem that some employees would have liked to be consulted about decisions, although most of these respondents did not explain which decisions they would have liked to be consulted on. One respondent suggested that the implementation of the Audit Integration of Management Systems (AIMS) project should have involved a wider consultative forum.

A fourth theme that emerged was that thr research was done at the wrong time since most of the employees were uncertain about their future at DIT. The AIMS project had already been established in order to conduct a broad, institution-wide, right sizing exercise to ensure the maximum utilisation of the DIT's resources at a minimum cost. Staff of DIT alleged that possible retrenchments were the probable outcome of this exercise. In other words, the AIMS project was symptomatic of employees' lack of trust in management.

\section{DISCUSSION}

The previous section presented results that were found to be significant and which enabled the hypotheses to be accepted. In this section, these findings are discussed and interpreted relative to the literature and the relationships between the variables are further examined.

\section{Goal Clarity}

According to Weber and Weber (2001:294), goal clarity is the degree to which employees precisely comprehend an organisation's goals and the means for achieving those goals. The results of the study indicate that DIT employees were unclear about the goals of the institution (see Table 3). Employees perceived a lack of vision and direction. The findings could have the following consequences according to the change management literature:

- Resistance to the change process,

- Limited or non-participation in the change process,

- Employees pulling in different directions in the absence of vision and objectives,

- Poor quality offerings,

- Low productivity.

The change process literature suggests possible causes of lack of goal clarity during any change process, some of the most important of which are indicated below.

The goals need to appeal to the employees' sense of purpose (Moran \& Brightman, 2001:112). Unappealing goals could be due to a lack of communication or proper communication. The change leadership group should communicate using a few forceful and memorable words (Covington, 2001:15). According to Appelbaum, St-Pierre, and Glavas (1998:293), lack of goal clarity may be attributable to the fact that employees might not conceptualise the link between the organisational goals and their individual jobs. The lack of goal clarity in DIT is an opportunity to reiterate the direction of the DIT institution in order to ensure that the merger is successful when it comes to the human aspect of change.

\section{Trust in Management}

Employees who trust management feel congruence with managerial values and react more positively to changes in organisational direction (Weber \& Weber, 2001:291). The results of the DIT study indicate that $58 \%$ of the responses were negative, which suggests a lack of trust in management (see Table 3 ). The results are consistent with the findings of the Anderson KPMG Consulting (2002:35) study looking at organisational climate within the Durban Institute of Technology. 
From the literature, it appears possible that the outcome of distrust within an organisation can include the following:

- Misunderstanding of change management initiatives,

- Resistance when people distrust or have past resentments toward those leading change,

- Employees' lack of motivation,

- Poor quality of service,

- Low productivity.

The change management literature suggests a number of possible causes of distrust within the organisation and includes the fact that trust does not occur on demand, but rather it is built over time (Borden, 1997:6). According to McLagan (2002:50), poor trust levels can be attributed to a lack of procedural justice during change, lack of objectivity and fairness. Feelings of uncertainty, lack of information about change, speculation and unfounded fears can also contribute to distrust (Borden, 1997:6; Barret, 2000:28 and Weber \& Weber, 2001:291). Better levels of trust might be achievable at the DIT in future since the merger took place formally only in April 2002, and the building of new trust might require longer than this.

\section{Perceptions of Organisational Readiness for Change}

Overall, the DIT employees felt that the organisation was not ready for change; hence $65 \%$ rated the readiness statements low as is shown in Table 3 . Such results suggest that successful change might not be realised. The consequences of employees' feelings might lead to the following:

- Resistance to the change process,

- Limited or non-participation in any change management initiatives,

- Attempts to sabotage the change process.

Commentary by various authors suggests that employees' perceptions of organisational readiness for change could be explained in a number of ways. Lack of on-going interactions might contribute to the negative results (White, 2000:165). Presence of experimental structures away from mainstream activities will improve innovation, hence preparing the organisation for change (Tabatoni, Davies \& Barblan, 2002:7). Any propensity to 'paralysis analysis', or a 'wait and see' attitude, creates an environment that is not conducive to change (Appelbaum, St-Pierre \& Glavas, 1998:290). Management actions and behaviour can create an atmosphere that is stifling (Roberts, 2003:3).

Establishing possible causes of employees' responses precisely would benefit the change process. The current study did not address the causes so further investigation is necessary. A focus group research design would probably be appropriate to explore behavioural elements, interventions, and practices that might inhibit success.

\section{The Relationship between Variables}

The results have indicated that the relationship between goal clarity and trust in management is positive and that the two variables are strongly correlated (as is shown in Table 5). The implication is that lack of goal clarity may lead to poor levels of trust in management. These results are consistent with previous research, which argues that clear goals provide a sense of purpose that fosters trust (Weber \& Weber, 2001:294). According to Borden (1997:6), most problems occur as a result of lack of trust and communication.

The findings further indicate that the relationship between goal clarity and employee perceptions of organisational readiness for change is positive and strongly correlated (see Table 5). The implication of this is that lack of goal clarity leads to poor organisational readiness for change. These results are consistent with arguments that say that when people know why the change is needed, they can figure out 
what to change and how to change it (Covington, 2001:15 and Moran \& Brightman, 2001:112). Managers set the tone and pace for employees by their actions and behaviour (Roberts, 2003:3).

The results also indicate that trust in management and the employees' perceptions of organisational readiness for change are positively and strongly correlated (see Table 5). These results imply that poor levels of trust in management lead to employees' perceiving that organisational readiness for change is low. The results are consistent with arguments that say that people are more willing to cooperate and support corporate decisions if they know that they will be well-informed along the way (Borden, 1997:6). People can allow changes that may affect them unfavourably if they believe the change is right and evenhandedness is followed (McLagan, 2002:50).

Since there was a strong, positive relationship amongst the three main variables, it is possible that other factors may also be related to the three variables investigated in this study. Such factors could either assist or hinder the change process. Future research on employee attitudes during change may identify additional opportunities for management to improve the success of transformation, which was initiated across the South African higher education institutions in 2004 and is set to continue.

It would seem that the sequence of events leading up to the merger, such as granting voluntary exit packages before the implementation of AIMS, hindered the change process at DIT. The consequence of this was that marketable individuals who were running, or working in, viable programmes took the exit packages. This was understandable, as DIT staff perceived that after completion of the AIMS project, all non-viable departments would be closed and staff retrenched.

\section{CONCLUSION}

The research findings indicate that goal clarity, trust in management and perceptions of organisational readiness for change need specific attention during any transformation to assist in success. The strong positive correlations among the research variables suggest that prioritising these issues is not an option, but a necessity. A merger should, in fact, not be instituted in a situation of poor goal clarity, lack of trust in management or perceptions of poor organisational readiness for change, but should be postponed until goal clarity and trust have been restored.

\section{Limitations}

The opinions of the respondents were consistent regarding issues raised. It must be noted however that the study was conducted at the same time as the Audit Integration of Management Systems (AIMS) project which was a comprehensive, institution-wide, right-sizing exercise to ensure the maximum utilisation of the DIT's resources, at a minimum cost. Its rationale was that DIT was operating at an unsustainable financial level and the long-term survival of the institution was at risk. The DIT staff perceived that the AIMS project could result in possible retrenchments, and this may have contributed to the negative sentiments revealed in this study. However, this could be seen as symptomatic of a lack of goal clarity and trust in management and thus does not mitigate against the findings.

\section{Recommendations}

Management efforts to identify and ensure clarity about organisational goals before and during a change initiative could help to improve employee attitudes. Goal clarity was a key aspect of developing and maintaining positive employee attitudes during the DIT change effort, and the change literature emphasises the importance of ensuring clarity of organisational goals (Covington, 2001:15 and Moran \& Brightman, 2001:112).

Establishing the possible causes of the employees' responses precisely would benefit the change process. The DIT study did not address the issue of what the frame of reference for the employees' responses was. Hence, further investigation is necessary. A focus group research design may be 
appropriate to explore elements of behaviours, interventions and practices that might contribute to success or restrict success of institutional mergers.

Since there is a strong positive relationship between the variables, the relationship might also imply that there are other factors that could be related to the variables of the study, either positively or negatively. Therefore, research is needed to identify and understand other variables affecting the success of the merger process. Future research on employees' attitudes during change may recognise additional opportunities for management to encourage the success of the ubiquitous organisational change initiative.

\section{REFERENCES}

Andersen KPMG Consulting. 2002. Durban Institute of Technology internal analysis - organisational climate survey. Report.

Appelbaum SH, St-Pierre N \& Glavas W. 1998. Strategic organisational change: the role of leadership, learning, motivation and productivity. Management Decision, 36(5):289-301.

Barret GA. 2000. Management's impact on behavioural safety. Professional Safety, 45(3):26-30.

Bennett H \& Durkin M. 2000. The effects of organisational change on employee psychological attachment: An exploratory study. Journal of Managerial Psychology, 15(2):126-146.

Bill L. 2002. How to deal with feelings during change. People Management, 18(8):54-55.

Borden SM. 1997. Technology can't take the place of trust. Journal of Management in Engineering, 13:26.

Buono AF. 2003. SEAM-less post-merger integration strategies: a cause for concern. Journal of Organisational Change Management, 16(1):90-98.

Chawla A \& Kelloway EK. 2004. Predicting openness and commitment to change. Leadership \& Organisational Development Journal, 25(6):485-498.

Cooper DR \& Schindler PS. 2001. Business Research Methods. $7^{\text {th }}$ ed. New York: McGraw-Hill.

Covington J. 2001. Leading Successful, Sustainable Change. Executive Excellence, 18(12):5.

Durban Institute of Technology. 2002. Statement from Professor Kader Asmal on the transformation and reconstruction of the higher education system. Monday Edition, 1(4):1-3.

Francis D, Bessant J \& Hobday M. 2003. Managing Radical Organisational Transformation. Management Decision, 41(1):18-31.

Jansen JD. 2002. Mergers in higher education: lessons learned in transitional contexts: Pretoria: UNISA

Jansen JD. 2004. How mergers shape the institutional curriculum. South African Journal of Higher Education, 18(1):5-18.

Kotler P, Wong V, Saunders J \& Armstrong G. 2005. Principles of Marketing. $4^{\text {th }}$ European ed. Harlow: Pearson Education.

LaClair JA \& Ravi PR. 2002. Helping employees embrace change. McKinsey Quarterly, 2(4):17-24.

McLagan PA. 2002. Success with change. TD, December:45-52. 
Mfusi XM. 2004. The effects of higher education mergers on the resultant curricula of the combined institutions. South African Journal of Higher Education, 18(1):98-110.

Mohyeldin A \& Suliman T. 2001. Are we ready to innovate? Work climate - Readiness to innovate relationship: The case of Jordan. Creativity and innovation management, 10(1):49-59.

Moran JW \& Brightman BK. 2001. Leading organisational change. Career Development International, 6(2):111-119.

Pick D. 2003. Framing and Frame Shifting in a Higher Education Merger. Tertiary Education and Management, 9(4):299-316.

Pounder JS. 2001. 'New Leadership' and universities' organisational effectiveness: exploring the relationship. Leadership and Organisation and Development Journal, 22(6):281-290.

Roberts RA. 2003. You want to improve? First you must change. Supervision, 64(5):3-8.

Roseel P. 2005. How deconstruction can be construction: inward and outward - bound academic entrepreneurship as drivers for change. Acta Academica, 37(2):212-264.

Rowley G. 1997. Mergers in Higher Education: A Strategic Analysis. Higher Education Quarterly, 51(3):251-263.

Senge P. 2006. The Fifth Discipline The Art \& Practice of The Learning Organisation. London: Random House.

Shalem S. 2001. Employee readiness for change within an organisational merger: Individual and contextual correlates. Masters in Industrial Psychology dissertation, Faculty of Arts, University of the Witwatersrand, Johannesburg.

South Africa. 1997. Higher Education Act 101 of 1997. Pretoria: Government Printer.

Stauffer D. 2003. How to Win the Buy-In: Setting the Stage for Change. Harvard Management Update, $6(8): 3,2$.

Steyn J \& de Klerk J. 2005. Karl Popper's Views on an Open Society and their Implications for the Democratic Transformation of South African Education. Education as Change, 1(9):151-167.

Struwig FW \& Stead GB. 2001. Planning, designing and reporting research. Cape Town: Hanli Venter Publisher.

Swanepoel A. 2005. Lessons learned from library mergers at colleges of higher education in Flanders. South African Journal of Libraries and Information Science, 71(1):85-92.

Tabatoni P, Davies J \& Barblan A. 2000. Strategic Management and Universities' Institutional Development. Paper read at the International Conference on Institutional Review Programme, Thema, EUA, Istanbul, 2000.

Weber PS \& Weber JE. 2001. Changes in employee perceptions during organisational change. Leadership and Organisation Development Journal, 22(6):291-300.

Welman JC, Kruger SJ \& Mitchell B. 2005. Research Methodology. 3rd ed. Cape Town: Oxford University Press. 
White L. 2000. Changing the 'Whole System' in the public sector. Journal of Organisational Change Management, 13(2):167-177.

Wyngaard A \& Kapp C. 2004. Rethinking and re-imaging mergers in further and higher education: human perspective. South African Journal of Higher Education, 18(1):185-200. 